\title{
Research Letter \\ Craniofacial Dyssynostosis in Two Boys With Apparently Normal Cognitive Development
}

\author{
Sam F. Lahidji, ${ }^{1}$ Steven R. Buchman, ${ }^{2}$ Karin Muraszko, ${ }^{3}$ Jeffrey W. Innis, ${ }^{4,5}$ \\ and Catherine E. Keegan ${ }^{5 *}$ \\ ${ }^{1}$ Medical School, University of Michigan, Ann Arbor, Michigan \\ ${ }^{2}$ Department of Surgery, Division of Plastic Surgery, University of Michigan, Ann Arbor, Michigan \\ ${ }^{3}$ Department of Neurosurgery, University of Michigan, Ann Arbor, Michigan \\ ${ }^{4}$ Department of Human Genetics, University of Michigan, Ann Arbor, Michigan \\ ${ }^{5}$ Department of Pediatrics, Division of Genetics, University of Michigan, Ann Arbor, Michigan
}

Received 21 November 2005; Accepted 15 March 2006

\section{How to cite this article: Lahidji SF, Buchman SR, Muraszko K, Innis JW, Keegan CE. 2006. Craniofacial dyssynostosis in two boys with apparently normal cognitive development. Am J Med Genet Part A 140A:1333-1336.}

\section{To the Editor:}

Craniofacial dyssynostosis (CFD) is a rare malformation syndrome characterized by lambdoid and/or posterior sagittal craniosynostosis and dysmorphic facial features. This syndrome was first described by Neuhauser et al. [1976] in a report of two siblings and five sporadic cases. Since then, a total of 14 cases have been reported in the literature [Al-Torki et al., 1998; Morton, 1998; Grosso et al., 2004; Bermejo et al., 2005]. We report two additional cases of CFD in boys with normal stature and relatively normal cognitive development.

The first patient was referred at 2 months for occipital prominence and dysmorphic facial features (Fig. 1A-C). He was the second child of healthy, nonconsanguineous parents. Family history was significant for a first cousin through a paternal aunt, evaluated elsewhere for unusual facial features including hypertelorism and a broad forehead, but without craniosynostosis. The father and paternal aunt were stated to have similar facial features, but were never formally evaluated by a geneticist. Paternal ancestry is unknown. Maternal ancestry is Melungeon [Kennedy and Kennedy, 1994].

The patient's anterior fontanel was enlarged, soft, and posteriorly placed. There was bony prominence of the lambdoid sutures and frontal bossing with flattening of the supraorbital ridges. The patient had low-set ears, a cupped left helix, proptosis, hypertelorism (interpupillary distance $5.5 \mathrm{~cm},>97$ th centile), midface hypoplasia, an upturned nose and micrognathia. Skin exam revealed a nevus flammeus on the glabella and on the nape of the neck. He also had bilateral partial soft tissue syndactyly of the 2 nd and 3rd toes. Head CT demonstrated bilateral lambdoid synostosis and possible synostosis of the posterior aspect of the sagittal suture (Fig. 2A,B). Head MRI revealed a small posterior fossa and foramen magnum but no evidence of tonsillar ectopia (Fig. 2C). Karyotype was 46, XY and DNA diagnostic studies for Crouzon (FGFR2, exons 8 and 10; FGFR3, exon 7), Muenke craniosynostosis (FGFR3, P250R), and SaethreChotzen (TWIST1) syndromes were negative.

Growth parameters were normal at 1 year with the exception of OFC at the 96th centile. Brain MRI showed development of type I Chiari malformation with $11 \mathrm{~mm}$ of tonsillar herniation, and cerebral angiogram revealed a serpiginous venous anomaly in left paracentral region. At 13 months, he developed increased ICP (opening pressure $25-26 \mathrm{~cm}$ water) and a ventriculoperitoneal shunt was placed. Three months later, he underwent a cranial vault reconstruction with fronto-orbital advancement. At 2 years, his head shape and size had improved following cranial vault reconstruction (Fig. 1D). He still had a prominent forehead, hypertelorism and down-slanting palpebral fissures, but no frontal bossing or prominent occiput and OFC had decreased to the 75th centile. Neuropsychological testing at 25 months revealed normal gross and fine motor development and mild expressive language delay.

*Correspondence to: Catherine E. Keegan, M.D., Ph.D., Department of Pediatric Genetics, University of Michigan, 3520 MSRB I, 1150 W. Medical Center Dr., Ann Arbor, MI 48109-0652. E-mail: keeganc@med.umich.edu DOI 10.1002/ajmg.a.31268 


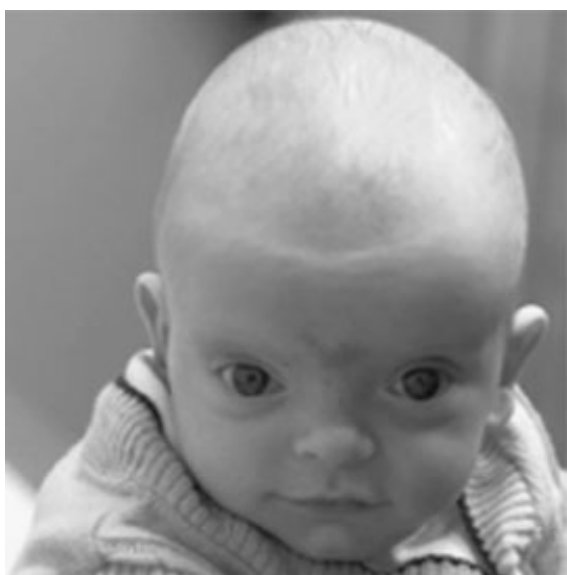

A

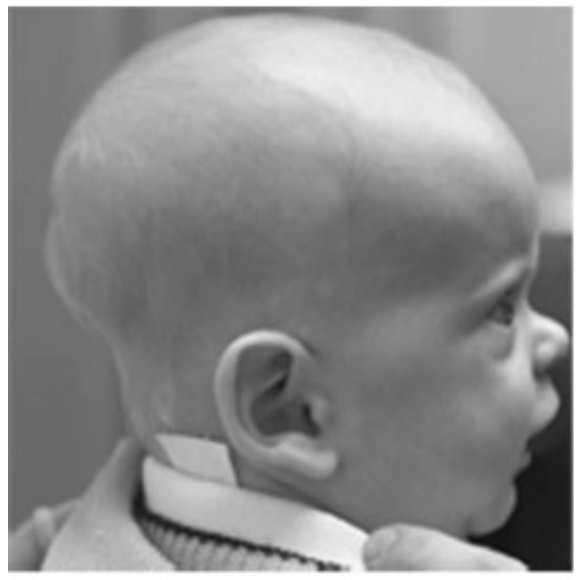

C

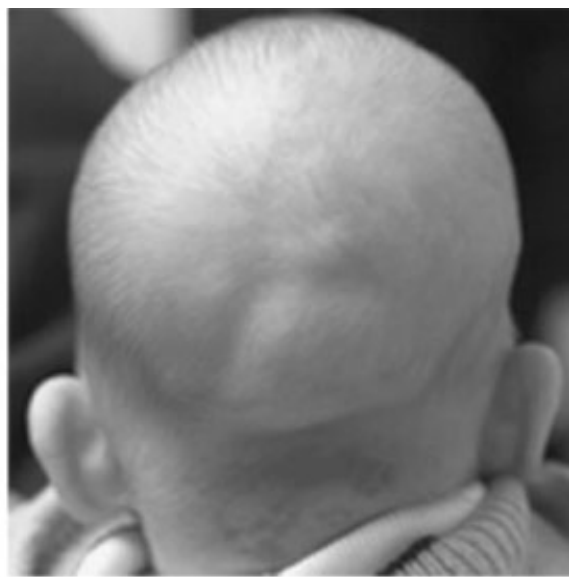

B

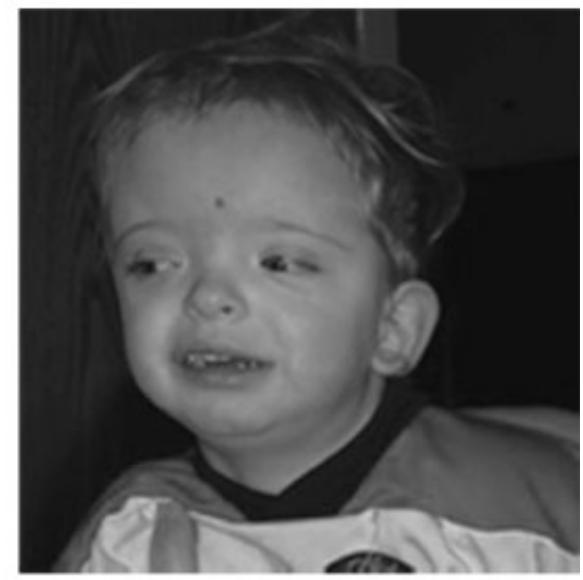

D

FIG. 1. Photographs of Patient 1 at age 3 months (A-C) and age 2 years 3 months (D)

Our second patient was born with frontal bossing, an elongated head and a prominent occiput. There was no family history of craniosynostosis. His father had a head circumference of $57.8 \mathrm{~cm}$ with a normal head shape and no occipital prominence. The parents were not consanguineous and were of mixed European descent. His past medical history was significant only for a pyloroplasty at age 6 weeks. At

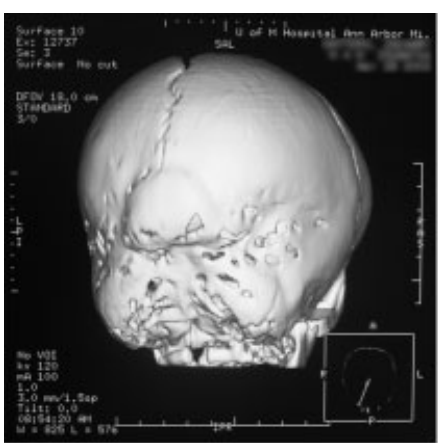

A

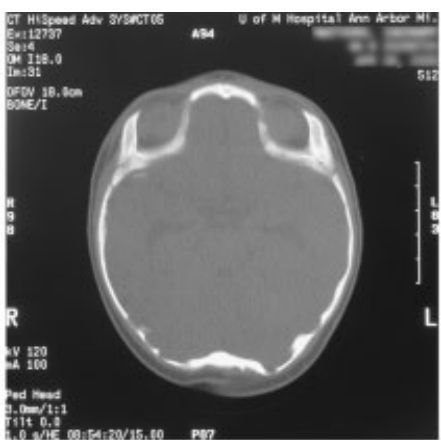

B

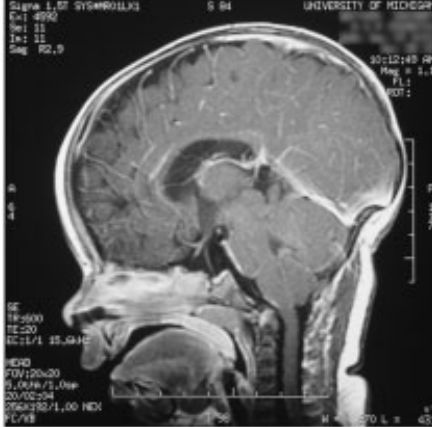

C

FIG. 2. Cranial imaging of Patient 1. Head CT with reformatted 3D images (A) and bone windows (B) at age $4 \frac{1}{2} \mathrm{months}$ demonstrates fusion of the bilateral lambdoid and posterior sagittal sutures. Sagittal T2 weighted brain MRI image $(\mathbf{C})$ at age $4 \frac{1}{2}$ months shows a small posterior fossa and foramen magnum, and a dysmorphic calvarium due to lambdoid craniosynostosis. The lateral ventricles are minimally dilated, and there is no evidence of a Chiari malformation at this time. Chiari I malformation was noted on a subsequent MRI at age 13 months. 


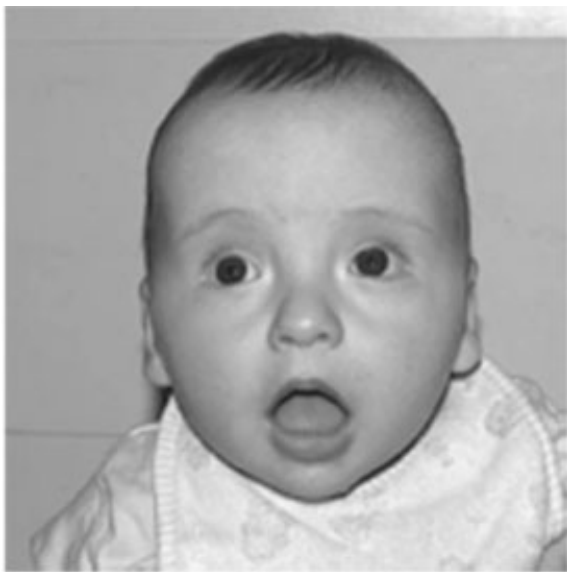

A

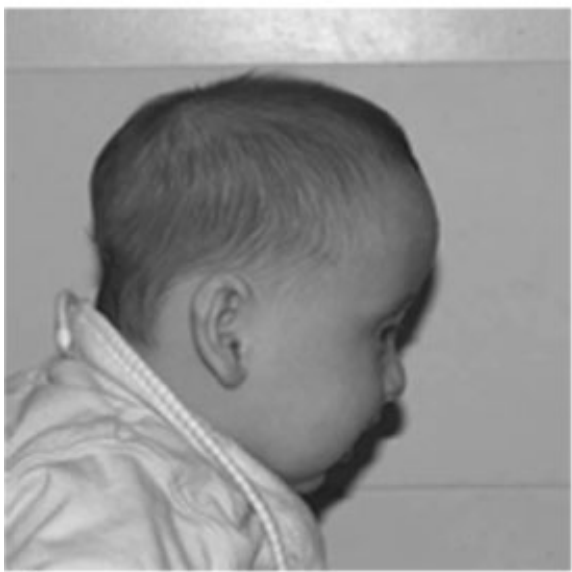

C

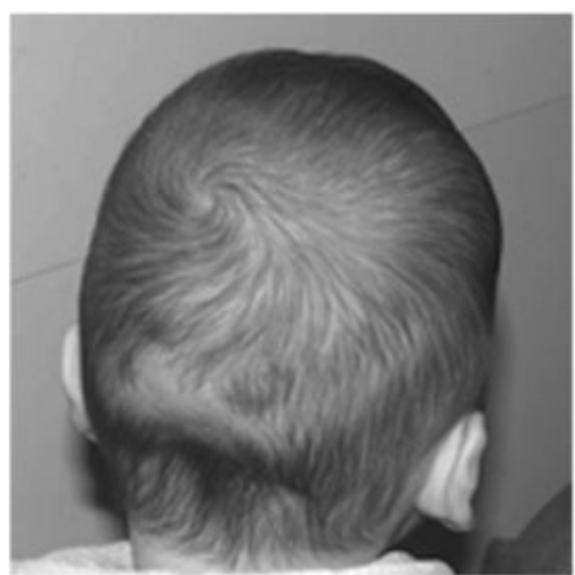

B

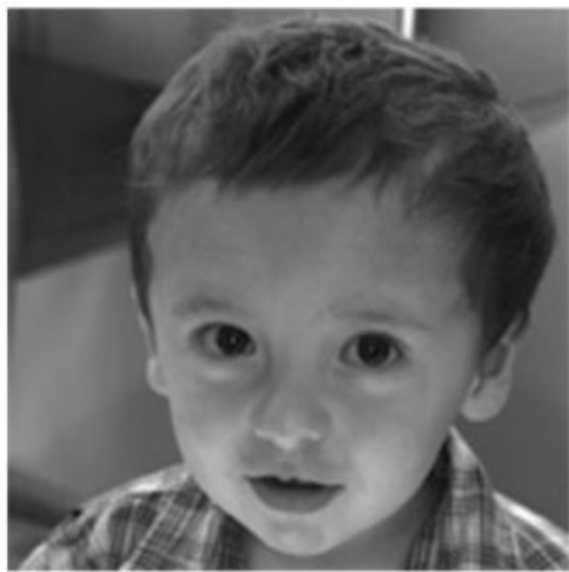

D

FIG. 3. Photographs of Patient 2 at age 5 months (A-C) and age 1 year 9 months $(\mathbf{D})$

5 months, he had a prominent point at the back of his head (Fig. 3A-C). Examination revealed bony ridging of the posterior portion of the sagittal suture and the lambdoid sutures. Head CT was significant for posterior sagittal and bilateral medial lambdoid synostoses. Brain MRI at 6 months showed evidence of mildly enlarged lateral ventricles and a type I Chiari malformation with tonsillar ectopia of $7-8 \mathrm{~mm}$ below the foramen magnum. The patient underwent a three-quarter cranial vault reconstruction of the posterior aspect of the skull at 7 months.

At age 1 year, his gross motor skills were mildly delayed, but he had no delays in fine motor skills, social skills or speech development. Growth parameters were normal, except for head circumference (49.4 cm; +2.5-3 SD). His facial features showed a broad forehead, high hairline, wide biparietal diameter, and a shelf-like prominence at the posterior skull (Fig. 3D). Interpupillary distance was at the 95 th centile $(5.1 \mathrm{~cm})$. He also had over-folded helices and thickened ear lobes bilaterally as well as a right single palmar crease. By 21 months, expressive language was delayed by approximately 6 months Otherwise, he was developmentally normal.

CFD is suggested in these two patients by the presence of bilateral lambdoid synostosis, synostosis of the posterior sagittal suture, frontal bossing, prominent occiput, large anterior fontanel, hypertelorism, and midface hypoplasia. The majority of reported CFD patients have had significant mental retardation and short stature. The pertinent characteristics from the literature are compared to the present patients in Table I.

Multiple CNS malformations have been described in patients with CFD, of which the most commonly reported are enlargement of the cerebral ventricles, agenesis of the corpus callosum, and sella turcica anomalies. Other malformations previously reported include brain atrophy, neural migration defect, subdural hygroma, spina bifida occulta, and enlarged subarachnoid space. Both patients in this report had evidence of ventricular enlargement and had, in addition, a Chiari I malformation, which is perhaps related to the significant bony abnormality 
TABLE I. Selected Clinical Features in Patients With Craniofacial Dyssynostosis

\begin{tabular}{|c|c|c|c|c|c|}
\hline & $\begin{array}{l}\text { Psychomotor } \\
\text { delay }\end{array}$ & $\begin{array}{c}\text { Mental } \\
\text { Retardation }\end{array}$ & $\begin{array}{l}\text { Speech } \\
\text { Delay }\end{array}$ & $\begin{array}{l}\text { Hydrocephalus/ } \\
\text { Enlarged ventricles }\end{array}$ & CNS malformation \\
\hline Neuhäuser 1 & - & - & - & - & - \\
\hline Neuhäuser 2 & + & + & - & - & - \\
\hline Neuhäuser 3 & + & + & + & + & Agenesis of corpus callosum, unusual veins in frontal region \\
\hline Neuhäuser 4 & + & + & - & + & o - \\
\hline Neuhäuser 5 & + & + & + & + & - \\
\hline Neuhäuser 6 & + & + & + & - & - \\
\hline Neuhäuser 7 & + & - & - & - & - \\
\hline Al-Torki & + & + & - & - & Agenesis of corpus callosum \\
\hline Morton & + & + & + & + & Thin corpus callosum, neuronal migration defect \\
\hline Grosso & + & + & + & - & Partial agenesis of corpus callosum \\
\hline Bermejo 1 & + & - & ?* & - & - \\
\hline Bermejo 2 & ?* & ?* & ?* & + & - \\
\hline Bermejo 3 & + & - & - & + & - \\
\hline Bermejo 4 & ?* & ?** & ?* & - & - \\
\hline Lahidji 1 & - & - & + & + & Type I Chiari, venous anomaly in left paracentral region \\
\hline Lahidji 2 & - & - & + & + & Type I Chiari \\
\hline
\end{tabular}

*Patient too young to be determined or information not reported.

associated with the lambdoid synostosis. The cause of hydrocephalus in the first patient was thought to be due to obstruction of CSF flow secondary to the abnormal crowding of the posterior fossa. This patient also had an unusual serpiginous region of venous effluence identified in the left paracentral region. This venous anomaly is of particular interest because of the previous report by Neuhauser et al. [1976] of unusual veins in the frontal area in Patient 3 (Table I).

Of importance, the developmental delays are less pronounced in our patients than in those previously described, lacking mental retardation, seizures, spasticity, or hypotonia, as reported earlier by Neuhauser et al. [1976], and later on found in almost all patients (Table I). Furthermore, the majority of previously reported CFD patients have had short stature, which was not present in our patients. Thus, our patients appear to represent the mild end of the spectrum of CFD cases.

It has been speculated that the mode of inheritance of CFD is autosomal recessive [Neuhauser et al., 1976]. Including our two male patients, there are now twelve males and four females with CFD documented in the literature. This adds to the speculation by Bermejo et al. [2005] as to whether there is equal penetrance between the two sexes, as would normally be observed in autosomal recessive inheritance. In addition, the lack of consanguinity in any identified case thus far may imply an alternative mode of inheritance in some patients with CFD. Both of our patients had facial characteristics in common with other family members who did not have craniosynostosis. Although these family members were not formally evaluated by a geneticist, we are making the assumption that they are not affected with CFD, but rather, these shared features are familial traits unrelated to CFD. Nevertheless, until the molecular basis of CFD is characterized, we cannot exclude autosomal dominant inheritance with reduced penetrance in the families of our two patients.

\section{ACKNOWLEDGMENTS}

The authors would like to thank the families of the patients presented in this report.

\section{REFERENCES}

Al-Torki NA, Sabry MA, Al-Tawari A, Al-Kandari NH, Al-Awadi SA. 1998. Craniofacial dyssynostosis with cryptorchidism and normal stature. Am J Med Genet 79:5-7.

Bermejo E, Felix V, Lapunzina P, Galan E, Soler V, Delicado A, Pantoja A, Marquez MD, Garcia M, Mora E, Cuevas L, Ureta A, Lopez-Pajares I, Martinez-Frias ML. 2005. Craniofacial dyssynostosis: Description of the first four Spanish cases and review. Am J Med Genet Part A 132A:41-48.

Grosso S, Vivarelli R, Muraca MC, Berardi R, Marconcini S, Morgese G, Balestri P. 2004. Craniofacial dyssynostosis: Case report and review. Am J Med Genet Part A 129A:300-302.

Kennedy BN, Kennedy RV. 1994. The Melungeons- The Resurrection of a Proud People. Macon, GA: Mercer University Press.

Morton JE. 1998. Craniofacial dyssynostosis: A further case report. Am J Med Genet 79:8-11.

Neuhauser G, Kaveggia EG, Opitz JM. 1976. Studies of malformation syndromes of man XXXIX: A craniosynostosiscraniofacial dysostosis syndrome with mental retardation and other malformations: "Craniofacial dyssynostosis". Eur J Pediatr 123:15-28. 